\title{
Fuzzy Linguistic
}

Knowledge Based

Behavior Extraction for

Building Energy

Management Systems

\section{6th International Symposium on Resilient Control Systems}

Dumidu Wijayasekara

Milos Manic

Craig Rieger

U.S. Department of Energy

National Laboratory

operated by

Battelle Energy Alliance

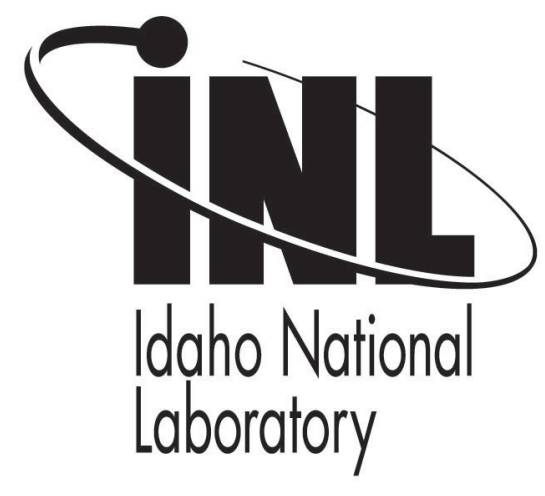

This is a preprint of a paper intended for publication in a journal or proceedings. Since changes may be made before publication, this preprint should not be cited or reproduced without permission of the author. This document was prepared as an account of work sponsored by an agency of the United States Government. Neither the United States Government nor any agency thereof, or any of their employees, makes any warranty, expressed or implied, or assumes any legal liability or responsibility for any third party's use, or the results of such use, of any information, apparatus, product or process disclosed in this report, or represents that its use by such third party would not infringe privately owned rights. The views expressed in this paper are not necessarily those of the United States Government or the sponsoring agency. 


\section{Fuzzy Linguistic Knowledge Based Behavior Extraction for Building Energy Management Systems}

\author{
Dumidu Wijayasekara, Milos Manic \\ University of Idaho \\ Idaho Falls, ID, USA \\ wija2589@vandals.uidaho.edu,misko@ieee.org
}

\author{
Craig Rieger \\ Idaho National Laboratory \\ Idaho Falls, ID, USA \\ craig.rieger@inl.gov
}

\begin{abstract}
Significant portion of world energy production is consumed by building Heating, Ventilation and Air Conditioning (HVAC) units. Thus along with occupant comfort, energy efficiency is also an important factor in HVAC control. Modern buildings use advanced Multiple Input Multiple Output (MIMO) control schemes to realize these goals. However, since the performance of HVAC units is dependent on many criteria including uncertainties in weather, number of occupants, and thermal state, the performance of current state of the art systems are sub-optimal. Furthermore, because of the large number of sensors in buildings, and the high frequency of data collection, large amount of information is available. Therefore, important behavior of buildings that compromise energy efficiency or occupant comfort is difficult to identify. This paper presents an easy to use and understandable framework for identifying such behavior. The presented framework uses human understandable knowledge-base to extract important behavior of buildings and present it to users via a graphical user interface. The presented framework was tested on a building in the Pacific Northwest and was shown to be able to identify important behavior that relates to energy efficiency and occupant comfort.
\end{abstract}

Keywords-HVAC; building energy efficiency; building occupant comfort, fuzzy logic; knowledge-base

\section{INTRODUCTION (Heading 1)}

Buildings worldwide consume more than $20 \%$ of total energy produced [1]. In the US around $40 \%$ of the energy production is consumed by buildings [1], [2]. This means that in the US more than $70 \%$ of the electricity production and over $50 \%$ of the natural gas production is consumed by buildings [3]. This also leads to buildings being one of the major causes of greenhouse gas production [4]. Buildings around the world account for more than $30 \%$ of greenhouse gas production [5] and the number is close to $40 \%$ in the US [3]. In many countries energy usage in buildings surpasses that of industry and transportation sectors [2].

Due to economic growth and the expansion of the building sector the energy usage in buildings has been steadily growing [2]. In 2008 the energy usage of buildings in North America has increased at an average rate of $1.9 \%$, and this number has been projected to further increase [1], [6]. This increase in energy usage has especially been attributed to Heating, Ventilation and Air Conditioning (HVAC) in buildings [1].

The largest energy consumer in buildings is HVAC systems [8]. Recent research have shown $30-50 \%$ of energy consumed in buildings is consumed by HVAC systems [2], [5], [8], [9]. Thus increasing energy efficiency in HVAC systems is an attractive proposition [10]. Recent research have shown that energy efficiency in HVAC systems can be improved more than $5 \%$ by implementing very low cost building management strategies [5]. Furthermore, it has been shown that the energy efficiency can be improved by up to $40 \%$ by closely monitoring the state of the building and improving control strategies [11], [12].

Since humans spend significant amount of time (nearly 90\%) indoors [13] human occupant comfort is also an important requirement of building HVAC. Furthermore, a comfortable work environment can improve productivity [14]. Human occupant comfort in buildings has been attributed to many factors such as temperature, humidity $\mathrm{CO}_{2}$ levels, etc. [15]. However, thermal comfort has been identified as the driving factor of overall comfort within buildings [15].

Therefore, building HVAC control is a multi criteria optimization problem that tries to maintain human occupant comfort while increasing the energy efficiency [16], [17]. In order to achieve these goals, modern buildings use advanced control systems known as Building Energy Management Systems (BEMSs). BEMSs are responsible for HVAC as well as lighting and other control aspects of buildings [16]. In order to achieve the goals of comfort and energy efficiency, BEMSs contain a large number of sensors throughout buildings and Air Handling Units (AHUs) and occupant zones [16], [18]. Using this gathered information BEMSs control an array of fans, dampers, and heating and cooling units. Thus, BEMSs are highly complex Multiple Input Multiple Output (MIMO) systems, and therefore are difficult to model [18]-[20].

Recently, large amount of research has been done on increasing the efficiency of BEMS while maintaining occupant comfort levels [12], [15]-[18], [21]-[25]. However, recent research is more focused on either increasing the efficiency of equipment or increasing the efficiency via control [26]. Very little work has been done in the area of situational awareness for building managers, and identifying sub-optimal behavior in existing BEMS [16], [27], [28].

Thus, this paper presents an easy to use framework for identifying important behavior of buildings that can be used to evaluate building performance. The presented framework utilizes expert provided fuzzy logic based linguistic rules to 


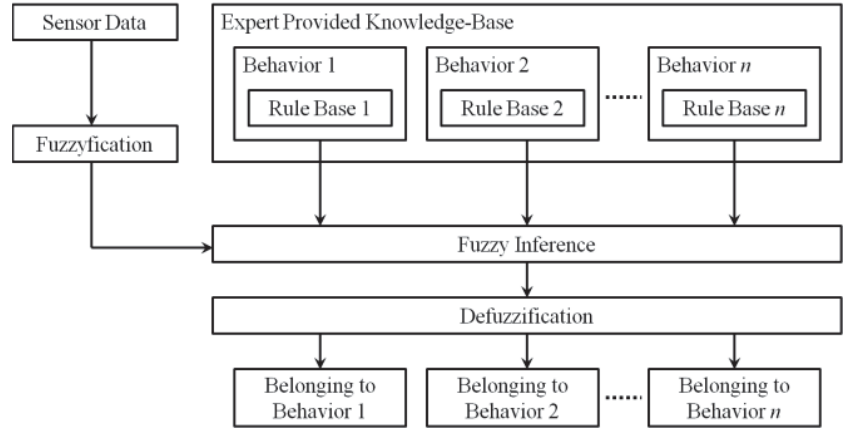

Fig. 1 Linguistic Knowledge-Based behavior extraction process

describe important behaviors of buildings. Using this knowledge-base, the current behavior of the building at a given time can be identified. The use of multiple rules enables the description of complex behavior of the building accurately. Fuzzy logic enables the description of behavior using human understandable rules that fuse information from multiple data sources. Furthermore, the use of fuzzy sets enables generalization of the rules for different types of buildings. An interactive Graphical User Interface (GUI) was created that presents the identified building behavior users in an easy to understand manner. The presented framework was tested on an office building in the Pacific Northwest, and was shown to be able to extract key information regarding occupant comfort as well as energy efficient building behavior.

The rest of the paper is organized as follows. Section II describes the presented framework in detail. Section III describes the implementation of the presented framework. Section IV presents experimental results and Section V concludes the paper.

\section{LingUISTIC RULE BASED BEHAVIOR EXTRACTION}

The highly complex MIMO nature of BEMSs leads to highly non-linear system states [18]. Furthermore, other highly uncertain sources as weather, thermal capacity of building, occupancy level, etc. have a high impact on the performance of BEMSs [19], [21], [22], [29]. Therefore, modeling BEMS performance using traditional methods is difficult [18]-[20]. However, it has been shown that fuzzy modeling is suited to model the non-linearity and interrelationships between different data sources existing in BEMSs [15], [17]. Similarly, human occupant comfort is also highly subjective, and also relies on a large number of factors [14], [20]. Fuzzy logic has been successfully used to model and describe building control as well as occupant comfort related aspects of BEMS [15], [18], [19].

The presented linguistic rule based behavior extraction framework utilizes a linguistic knowledge-base that consists of expert provided fuzzy rules. The fuzzy rules take form of Mamdani rules where outputs themselves are described in terms of fuzzy sets [30]. The framework is based on the three main steps of fuzzy inference: 1) fuzzification, 2) fuzzy inference, and 3) defuzzification [30]. Using the knowledgebase and sensor input, the framework can identify system behavior via the fuzzy inference process. Fig. 1 shows a block

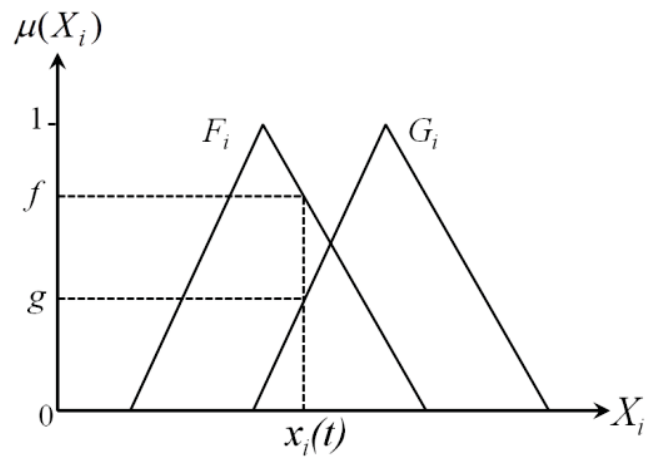

Fig. 2 Fuzzification of input parameter $X_{i}$

diagram of the framework process. Next each step of the process is discussed in detail.

The inputs to the behavior extraction framework are gathered sensor data from throughout the building. Thus for a building with $s$ number of sensors a single data point at time $t$ is a vector taking the form:

$$
\vec{D}(t)=\left\{x_{1}(t), x_{2}(t), \ldots, x_{s}(t)\right\}
$$

Where $\vec{D}(t)$ is the data point at time $t, x_{i}(t)$ is the value for the $i^{\text {th }}$ sensor input $X_{i}$ at time $t$.

In the fuzzification step, the real valued sensor data is converted in to a linguistic fuzzy term. Fig. 2 shows the fuzzification of an input sensor $X_{i}$ for the value $x_{i}(t)$. The domain of $X_{i}$ is divided into 2 fuzzy sets $F_{i}$ and $G_{i}$. These fuzzy sets represent human understandable terms describing the input domain such as Low and High. The degree of belonging of the value $x$ to the fuzzy set $F_{i}$ is represented as $\mu_{F_{i}}\left(x_{i}(t)\right)$. Thus:

$$
\mu_{F_{i}}\left(x_{i}(t)\right)=f
$$

And,

$$
\mu_{G_{i}}\left(x_{i}(t)\right)=g
$$

Each input dimension can be decomposed in to multiple fuzzy sets and fuzzy sets can take different shapes. Similarly, all input dimensions can be fuzzified and these fuzzified inputs are used in the next steps.

The expert provided knowledge-base consists of linguistic implicative fuzzy rules. An implicative fuzzy rule with $m$ number of antecedents takes the form:

$$
\begin{aligned}
& \text { Rule } R_{k} \text { : IF } X_{1} \text { is } A_{1}^{k} \text { AND ... AND } X_{m} \text { is } A_{m}^{k} \\
& \text { THEN Behavior } Y \text { is } B^{k}
\end{aligned}
$$

Where $X_{i}$ are antecedents of the rule and the consequent is $Y$. $A_{i}^{k}$ and $B^{k}$ are fuzzy sets defined for each dimension. The antecedents of a behavior extraction rule are various sensors inputs and the consequent is a specific behavior of the building induced by the sensor values described in the rule. The number of antecedents for a rule is bound by the number of sensors in the building $s$ : 
TABLE I

LIST OF EXTRACTED ATTRIBUTES AND THEIR SCOPE

\begin{tabular}{c|c}
\hline \hline Attribute & Scope \\
\hline \hline Time & Building \\
\hline Outside Air Temperature & Building \\
\hline Chiller Temperature & Floor \\
\hline Mixed Air Temperature & Floor \\
\hline Return Air Temperature & Floor \\
\hline Damper Position & Floor \\
\hline Exhaust Fan Load & Floor \\
\hline Exhaust Fan Current & Floor \\
\hline Supply Fan Load & Floor \\
\hline Supply Fan Current & Floor \\
\hline Zone Temperature & Zone \\
\hline \hline
\end{tabular}

$$
1 \leq m \leq s
$$

Each significant behavior in the knowledge-base can have multiple rules in order to describe the behavior more thoroughly.

The fuzzy inference step takes the rules in the knowledgebase and fuzzified inputs to identify current building behavior. In order to identify the correct behavior given by the sensor values, the firing strength of each rule is calculated using:

$$
\mu_{R_{k}}(\vec{D}(t), Y)=\min _{j=1 \ldots m}\left\{\mu_{A_{j}^{k}}\left(x_{j}(t)\right)\right\}
$$

Where, $\mu_{R_{k}}(\vec{D}(t), Y)$ is the firing strength of rule $k$ of behavior $Y$ for the data point $\vec{D}(t)$ at time $t . m$ is the number of antecedents in rule $k$ and $\mu_{A_{j}^{k}}\left(x_{j}(t)\right)$ is the fuzzified output of value $x_{j}(t)$ for sensor $X_{j}$.

Once the firing strengths of all the rules have been calculated, the aggregate output for each behavior is calculated. Assuming there are $K$ distinct rules for behavior $Y$, the aggregate output is calculated using:

$$
C(Y)=\bigcup_{k=1}^{K} \mu_{R^{k}}(\vec{D}(t), Y)
$$

Where $C(Y)$ is the aggregate output for behavior $Y$ and $\cup$ is the union operator for fuzzy sets.

The final step of the fuzzy rule based behavior extraction is defuzzification. In the defuzzification step the aggregate fuzzy output of the fuzzy inference process is converted to a real valued output. This is done by calculating the center of gravity (COG) of the aggregate output. The defuzzification step yields an output that relates the current building behavior to the behaviors explained in the knowledge-base. Using these values the current performance of the building can be evaluated by building managers.

\section{IMPLEMETED FRAMEWORK}

The fuzzy knowledge based behavior extraction framework was implemented for an office building in the Pacific

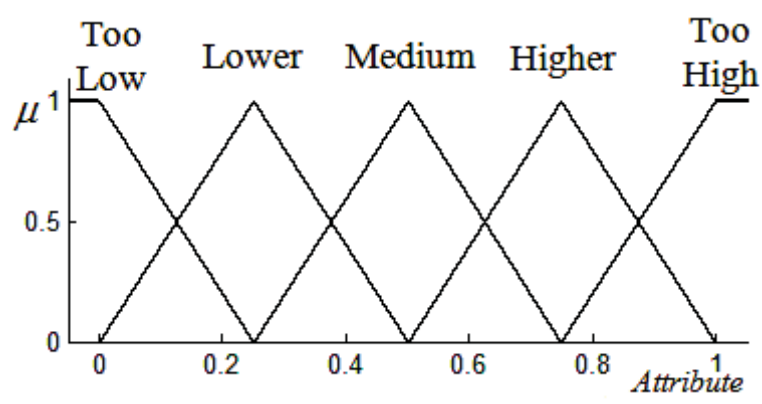

(a)

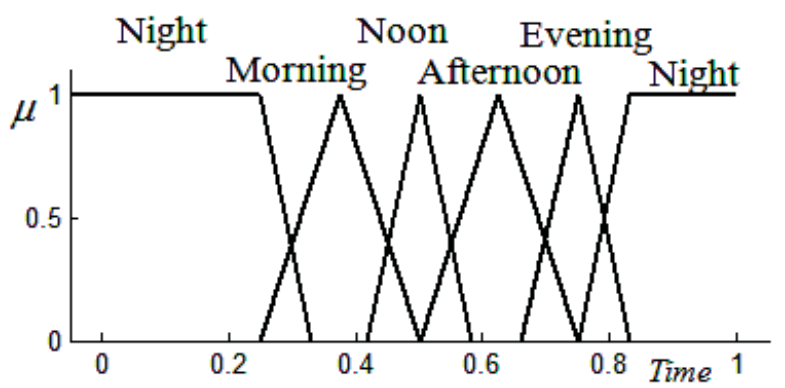

(b)

Fig. 3Representation of input domain in fuzzy linguistic terms (a) sensor input, (b) time attribute

Northwest. The building consists of 11 floors, where each floor has between 10 and 60 different measured occupant zones. Various sensors are available throughout the building measuring attributes related to individual occupants' zones, entire floors or the entire building.

For the purpose of experimental demonstration, 11 attributes were identified. The extracted attributes cover the scope of the building, specific Air Handling Units (AHUs) and occupant zones. These attributes together with their scope are listed in Table I.

\section{A. Fuzzy Logic Systems}

All attribute values were first normalized into a unit interval between 0 and 1 . Next the domain of the input attributes was represented using 5 triangular and trapezoidal fuzzy sets as denoted in Fig. 3(a) with the exception of the time attribute, which was represented using 6 fuzzy sets as denoted in Fig. 3(b). These fuzzy partitions represent a suitable decomposition of the respective domains established with respect to the targeted application.

As mentioned, the two main requirements of BEMS are energy efficiency and occupant comfort. Therefore, in this paper, energy efficiency and comfort related behaviors of the building were extracted using two linguistic rule sets. The energy efficiency and occupant comfort was described using the fuzzy sets shown in Fig. 4(a) and Fig. 4(b) respectively. Thus a "Low" efficiency or comfort will result in a negative output and a "High" output will result in a positive output. If none of the rules for a specific behavior is fired the output for that behavior will be 0 , which is the "Normal" behavior. 


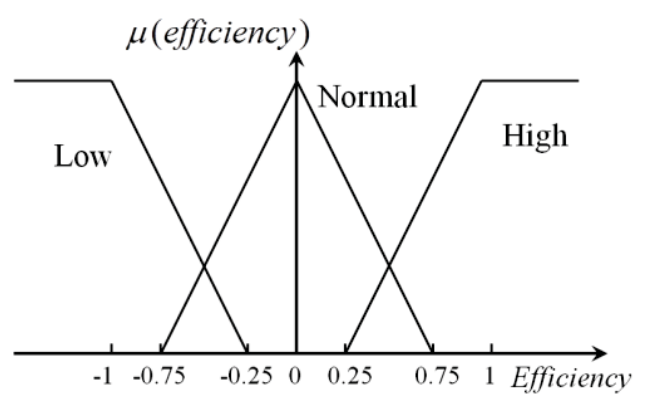

(a)

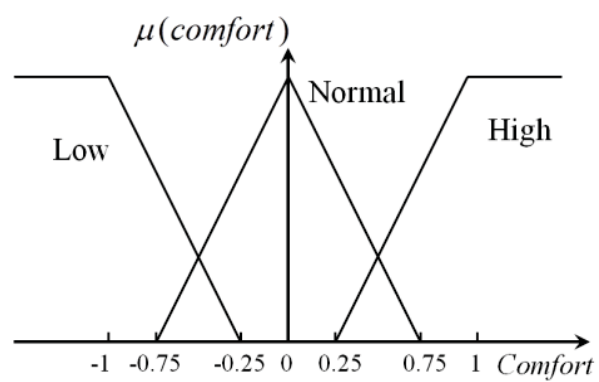

(b)

Fig. 4 Representation of the output domain using fuzzy linguistic labels: (a) energy efficiency, (b) occupant comfort

\section{B. Graphical User Interface}

In order to present the identified behavior in an understandable manner, a Graphical User Interface (GUI) was developed. Fig. 5 depicts the Graphical User Interface (GUI) developed for the framework.

The GUI contains three main information views: the building view (Fig. 5(a)), the floor view (Fig. 5(b)) and the data view (Fig. 5(c)). The building view provides a summary view of all floors in the building, where color can be assigned to depict various information, such as average floor temperature or the existence of important performance related information.

The floor view (Fig. 5(b)) shows the floor plan of the selected floor. The color of each zone depicts either the average temperature or energy efficiency or comfort levels. Low energy efficiency and comfort is encoded in red and high energy efficiency and comfort is encoded in blue. Normal energy efficiency and comfort levels are depicted in green color.

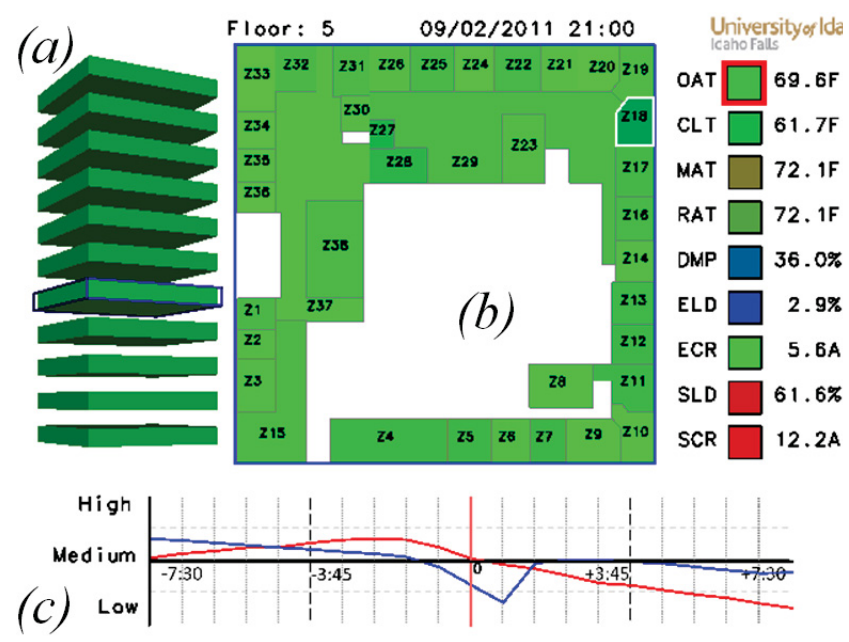

Fig. 5 Implemented Graphical User Interface (GUI) with the building (a), floor (b), and data views (c)

Finally, the user can select a specific zone for the given floor and observe the source data plotted over time. The building manager can plot multiple sources of data in the data view (Fig. 5(c)).

\section{EXPERIMENTAL RESULTS}

As mentioned, the presented framework was first tested on an office building in the Pacific Northwest. The behavior identification framework was used to identify energy efficiency and occupant comfort related behavior. For demonstration purposes and for the sake of simplicity, energy efficiency and occupant comfort were described using 4 rules each. This simplified linguistic knowledge-base of rules is shown in Table II. If none of the rules in Table II are fired, then the output of the fuzzy system is 0 , which correlates to normal behavior (see Fig. 4).

Three scenarios of behaviors extracted related to efficiency are shown in Fig. 6. Fig. 6 (a) shows a low efficiency behavior occurring at night where the zone temperature was high $\left(81^{\circ} \mathrm{F}\right)$ when the chiller temperature was low $\left(54^{\circ} \mathrm{F}\right)$. Clearly this indicates a low efficiency behavior since the chiller does not seem to be cooling the zone. Similar behavior is shown in Fig. 6 (b) where the zone temperature was high $\left(77^{\circ} \mathrm{F}\right)$ during the night when the outside air temperature was low $\left(59^{\circ} \mathrm{F}\right)$. Both the behaviors may be indicating unnecessary heating taking

TABLE II

LINGUISTIC KNOWLEDGE-BASE FOR BEHAVIOR EXTRACTION

\begin{tabular}{c|c}
\hline \hline Building Behavior & Linguistic Rule \\
\hline \hline \multirow{4}{*}{ Energy Efficiency } & IF Zone Temperature IS High AND Outside Air Temperature IS Low AND Time IS Night THEN Efficiency IS Low \\
\cline { 2 - 2 } & IF Chiller Temperature IS Low AND Zone Temperature IS High THEN Efficiency IS Low \\
\cline { 2 - 2 } Comfort & IF Outside Air Temperature IS High AND Zone Temperature IS Low THEN Efficiency IS Low \\
\cline { 2 - 2 } & IF Outside Air Temperature IS Low AND Zone Temperature IS High THEN Efficiency IS Low \\
\cline { 2 - 2 } & IF Zone Temperature IS Medium THEN Comfort IS High \\
\cline { 2 - 2 } & IF Time IS Morning AND Outside Air Temperature IS Low AND Zone Temperature IS Low THEN Comfort IS Low \\
\hline \hline
\end{tabular}




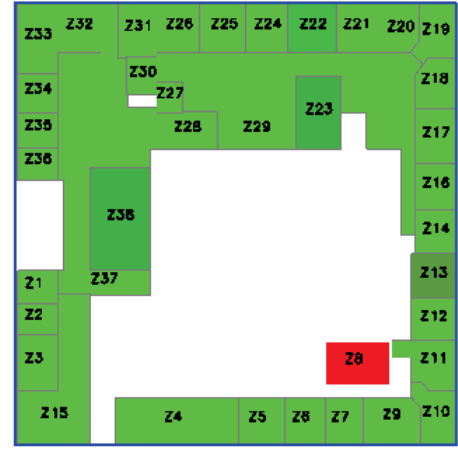

(a)

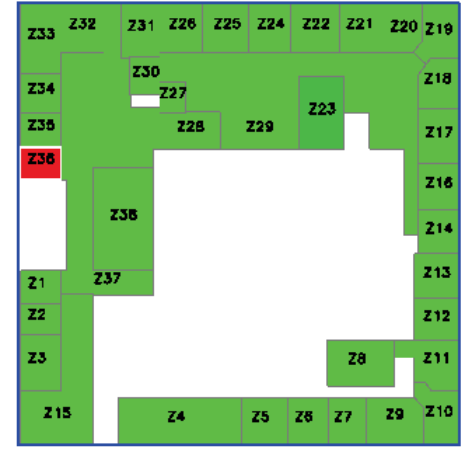

(b)

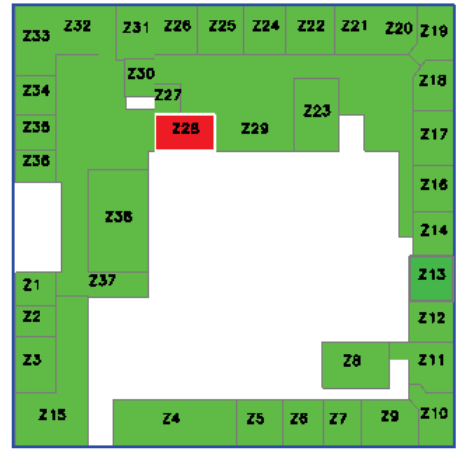

(c)

Fig. 6 Efficiency related behavior extracted: (a) High zone temperature at when chiller temperature was low, (b) High zone temperature at night when outside air temperature was low (c) High zone temperature when outside air was low during the day

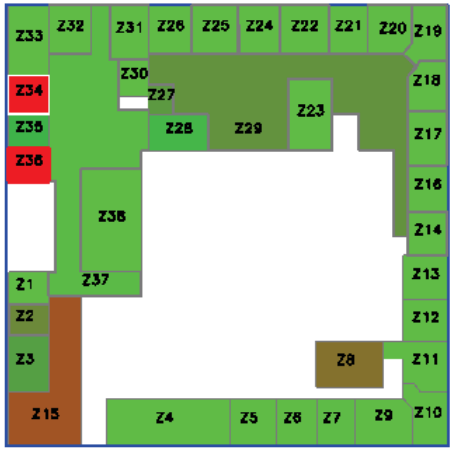

(a)

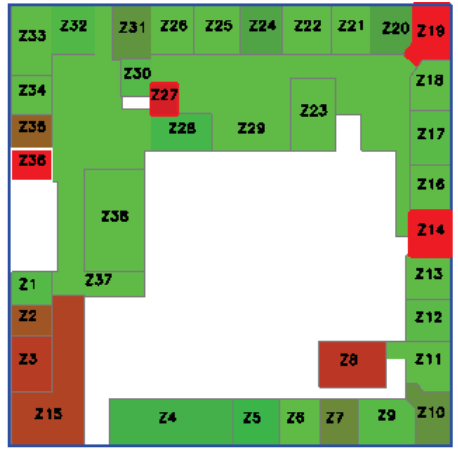

(b)

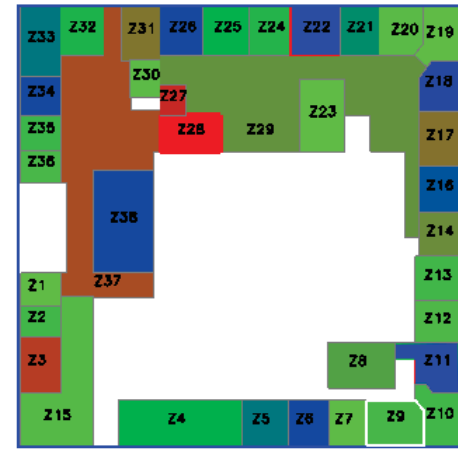

(c)

Fig. 7 Occupant comfort related behavior extracted: (a) Very low zone temperatures during the day, (b) Low zone temperatures in the morning (c) High and low comfort levels during the day

place at night when the building is closed. Fig. 6 (c) shows a behavior where the BEMS was not utilizing the outside air to cool a zone. Here the zone temperature was $79^{\circ} \mathrm{F}$ while the outside air temperature was $61^{\circ} \mathrm{F}$.

Similarly, three scenarios where the presented framework extracted occupant comfort related behavior is shown in Fig. 7. Fig 7 (a) and Fig 7 (b) show behavior where the occupant comfort was low because the zone temperature was low. Fig. 7 (a) shows two areas with zone temperatures below $62^{\circ} \mathrm{F}$ during the day. Several other zones were also marked as lower comfort. Similarly Fig 7 (b) shows several areas with zone temperatures below $65^{\circ} \mathrm{F}$ in the morning. Fig 7 (c) shows behavior relating to high occupant comfort (marked in blue), normal occupant comfort (marked in green) and low occupant comfort (marked in red) occurring during the day.

Thus, the presented framework was capable of extracting important building performance related behavior of buildings. This information can be used by the building managers to identify and eliminate low efficiency and low comfort behavior to realize the performance goals of BEMSs.

\section{CONCLUSIONS}

This paper presented an easy to use, understandable framework for identifying important building behavior. The presented framework utilizes a linguistic knowledge-base comprised of implicative fuzzy rules to describe complex behavior of the building, and is capable of fusing multiple sources of data to correctly identify important building behavior.

The presented system was tested on an office building in the Pacific Northwest and was shown to be able to identify important building behavior related to energy efficiency and human comfort. Furthermore, the framework uses an easy to understand GUI to present the identified behavior to building managers.

Future work includes testing the generalizability of the presented framework by applying the same knowledge-base to a different building. The complexity of the rule sets can be increased in the future to be applicable to a larger array of buildings. The GUI will be updated so that users can select distinct rules for behavior extraction. Furthermore, the behaviors extracted from the presented framework can be used to evaluate the performance of the building automatically.

\section{ACKNOWLEDGMENT}

This work was supported by the U.S. Department of Energy under DOE Idaho Operations Office Contract DEAC07-05ID14517, performed as part of the Center for Advanced Energy Studies (CAES), and the Instrumentation, 
Control, and Intelligent Systems (ICIS) Distinctive Signature of Idaho National Laboratory.

\section{REFERENCES}

[1] L.P. Lombard, J. Ortiz, C. Pout, "A review on buildings energy consumption information," Energy and Buildings, vol. 40, pp. 394-398, 2008.

[2] T. Kalamees, K. Jylhä, H. Tietäväinen, J. Jokisalo, S. Ilomets, R. Hyvönen, S. Saku, "Development of weighting factors for climate variables for selecting the energy reference year according to the EN ISO 15927-4 standard," Energy and Buildings, vol. 47, pp. 53-60, Apr. 2012.

[3] Buildings Energy Data Book, U.S. Dept. Energy, Washington, DC, 2009. [Online]. Available: http://buildingsdatabook.eren.doe.gov/.

[4] J. Lausten, "Energy Efficiency Requirements in Building Codes," Energy Efficiency Policies for New Buildings. Paris, France: International Energy Agency, 2008.

[5] A. Costa, M. M. Keane, J. I. Torrens, E .Corry, "Building operation and energy performance: Monitoring, analysis and optimisation toolkit," Applied Energy, vol. 101, pp. 310-316, Jan. 2013.

[6] T. Weng, Y. Agarwal, "From Buildings to Smart Buildings - Sensing and Actuation to Improve Energy Efficiency," IEEE Design \& Test of Computers, vol.29, no.4, pp. 36-44, Aug. 2012.

[7] B. Sun, P. B. Luh, Q. Jia, Z. O'Neill, F. Song, "Building Energy Doctors: An SPC and Kalman Filter-Based Method for System-Level Fault Detection in HVAC Systems," IEEE Trans. On Automation Science and Engineering, in press.

[8] K. W. Roth, D. Westphalen, J. Dieckmann, S. D. Hamilton, W. Goetzler, "Energy Consumption Characteristics of Commercial Building HVAC Systems: Volume III, Energy Savings Potential," TIAX LLC Report for US Department of Energy Building Technologies Program, 2002.

[9] B. Sun, P. B. Luh, Q. Jia, Z. Jiang, F. Wang, C. Song, "Building Energy Management: Integrated Control of Active and Passive Heating, Cooling, Lighting, Shading, and Ventilation Systems," IEEE Trans. on Automation Science and Engineering, in press.

[10] A. Aswani, N. Master, J. Taneja, D. Culler, C. Tomlin, "Reducing Transient and Steady State Electricity Consumption in HVAC Using Learning-Based Model-Predictive Control," Proceedings of the IEEE, vol. 100, no. 1, pp. 240-253, Jan. 2012.

[11] N. Motegi, M. A. Piettem S. K. Kinney, J. Dewey, "Case studies of energy information systems and related technology: operational practices, costs and benefits," in Proc. of International Conference for Enhanced Building Operators, Oct. 2003.

[12] K. Whitehouse, J. Ranjan; J. Lu, T. Sookoor, M. Saadat, C. M. Burke, G. Staengl, A. Canfora, H. Haj-Hariri, "Towards Occupancy-Driven Heating and Cooling," IEEE Design \& Test of Computers, vol. 29, no. 4, pp. 17-25, Aug. 2012.

[13] S. Bhattacharya, S. Sridevi, R. Pitchiah, "Indoor air quality monitoring using wireless sensor network," in Proc. of Sixth International Conference on Sensing Technology, pp. 422-427, Dec. 2012.

[14] I. J. Aucamp, L. J. Grobler, "Heating, ventilation and air conditioning management by means of indoor temperature measurements," in Proc. of Industrial and Commercial Use of Energy Conference (ICUE), pp.1-4, Aug. 2012.

[15] P. Bermejo, L. Redondo, L. de la Ossa, D. Rodríguez, J. Flores, C. Urea, J. A. Gámez, J. M. Puerta, "Design and simulation of a thermal comfort adaptive system based on fuzzy logic and on-line learning," Energy and Buildings, vol. 49, pp. 367-379, Jun. 2012.

[16] O. Linda, D. Wijayasekara, M. Manic, C. Rieger, "Computational Intelligence based Anomaly Detection for Building Energy Management Systems," in Proc. of IEEE Symposium on Resilience Control Systems, Aug. 2012.

[17] H. Mirinejad, K. Welch, L. Spicer, "A review of intelligent control techniques in HVAC systems," in Proc. of IEEE Energytech, pp. 1-5, May 2012.

[18] Z. Raad, K. S. M. S. Homod, A. F. Haider F. Almurib, "Gradient autotuned Takagi-Sugeno Fuzzy Forward control of a HVAC system using predicted mean vote index," Energy and Buildings, vol. 49, pp. 254-267, Jun. 2012.

[19] Z. Raad, K. S. M. S. Homod, A. F. Haider F. Almurib, "RLF and TS fuzzy model identification of indoor thermal comfort based on PMV/PPD," Building and Environment, vol. 49, pp. 141-153, Mar. 2012.

[20] Y. Cheng, J. Niu, N. Gao, "Thermal comfort models: A review and numerical investigation," Building and Environment, vol. 47, pp. 13-22, Jan. 2013.

[21] K. Macek, K. Mařík, "A methodology for quantitative comparison of control solutions and its application to HVAC (heating, ventilation and air conditioning) systems," Energy, vol. 44, no. 1, pp. 117-125, Aug. 2012 .

[22] F. Oldewurtel, D. Sturzenegger, M. Morari, "Importance of occupancy information for building climate control," Applied Energy, vol. 101, pp. 521-532, Jan. 2013.

[23] A. Kusiak, G. Xu, "Modeling and optimization of HVAC systems using a dynamic neural network," Energy, vol. 42, no. 1, pp. 241-250, Jun. 2012.

[24] P. M. Ferreira, A. E. Ruano, S. Silva, E. Z. E. Conceição, "Neural networks based predictive control for thermal comfort and energy savings in public buildings," Energy and Buildings, vol. 55, pp. 238251, Dec. 2012

[25] M. Maasoumy, A. Sangiovanni-Vincentelli, "Total and Peak Energy Consumption Minimization of Building HVAC Systems Using Model Predictive Control," IEEE Design \& Test of Computers, vol. 29, no. 4, pp. 26-35, Aug. 2012.

[26] A. Aswani, N. Master, J. Taneja, V. Smith, A. Krioukov, D. Culler, C. Tomlin, "Identifying models of HVAC systems using semiparametric regression," in Proc. of American Control Conference (ACC), pp. 36753680, Jun. 2012.

[27] L. Pérez-Lombard, J. Ortiz, I. R. Maestre, J. F. Coronel, "Constructing HVAC energy efficiency indicators," Energy and Buildings, vol. 47, pp. 619-629, Apr. 2012.

[28] G. Escrivá-Escrivá, O. Santamaria-Orts, F. Mugarra-Llopis, "Continuous assessment of energy efficiency in commercial buildings using energy rating factors," Energy and Buildings, vol. 49, pp. 78-84, Jun. 2012.

[29] S. Goyal, H. A. Ingley, P. Barooah, "Effect of various uncertainties on the performance of occupancy-based optimal control of HVAC zones," in Proc. of IEEE Conf. on Decision and Control (CDC), pp. 7565-7570, Dec. 2012.

[30] L. A. Zadeh, "Fuzzy logic," Computer, vol. 21, no. 4, pp. 83-93, Apr. 1988. 